\title{
Activating IRAK1 Gene Mutation
}

National Cancer Institute

\section{Source}

National Cancer Institute. Activating IRAK1 Gene Mutation. NCI Thesaurus. Code C157595.

A change in the nucleotide sequence of the IRAK1 gene that that results in constitutive activation of both interleukin-1 receptor-associated kinase 1 protein and its downstream signaling pathways. 